\title{
Synthesis of Hydrogel Film Based on Carrageenan Extracted from Kappaphycus alvarezii
}

\author{
Sperisa Distantina ${ }^{1,2}$, Rochmadi $^{1}$, Mohammad Fahrurrozi ${ }^{1}$ \& Wiratni ${ }^{1}$ \\ ${ }^{1}$ Department of Chemical Engineering, Gadjah Mada University, Yogyakarta, Indonesia \\ ${ }^{2}$ Department of Chemical Engineering, Sebelas Maret University, Surakarta, Indonesia \\ Correspondence: Sperisa Distantina, Department of Chemical Engineering, Sebelas Maret University, J1. Ir. \\ Sutami 36 A, Surakarta 57126, Indonesia. Tel: 62-274-632-112. E-mail: distantina@uns.ac.id
}

\author{
Received: May 3, $2013 \quad$ Accepted: June 27, $2013 \quad$ Online Published: July 5, 2013 \\ doi:10.5539/mas.v7n8p22 URL: http://dx.doi.org/10.5539/mas.v7n8p22
}

\begin{abstract}
Hydrogel based on kappa carrageenan extracted from Kappaphycus alvarezii was synthesized by film immersion in glutaraldehyde solution (GA 4\% w/w) as crosslinker for 2 min and then followed by thermal curing at $110{ }^{\circ} \mathrm{C}$ for $25 \mathrm{~min}$. The obtained crosslinked films were washed using ethanol to remove the unreacted crosslinker and finally dried to constant weight. The aim of this research was to investigate the effect of carrageenan recovery method on the prepared hydrogel properties. The method of carrageenan extraction strongly determined the swelling properties of crosslinked carrageenan. Hydrogel obtained from alkali treated carrageenan showed higher swelling ability compared to hydrogel from nonalkali treated carrageenan. Hydrogel from alkali treated carrageenan showed the ability of sensitive to $\mathrm{pH}$ media. Swelling degree of alkali treated carrageenan based hydrogels increased by increasing $\mathrm{pH}$ solution from about $5 \mathrm{~g} / \mathrm{g}$ for neutral $\mathrm{pH}$ to $20 \mathrm{~g} / \mathrm{g}$ for $\mathrm{pH} 13$.
\end{abstract}

Keywords: hydrogel, kappa carrageenan, glutaraldehyde, swelling, Kappaphycus alvarezii

\section{Introduction}

Hydrogels are tridimensional networks of hydrophilic polymers which are able to swell in water. Hydrogel ability to swell in response to external stimuli as $\mathrm{pH}$, ionic strength, temperature, electric fields depends on the nature of polymer chains and allows hydrogels useful in application such as controlled drug delivery, separation process or agricultural application (Hoffman, 2002; Gerlach et al., 2005; Peppas, 2004; Samchenko et al., 2011). Nowadays, preparation of hydrogels based on natural polymers especially polysaccharides have been explored extensively. Compared to synthetic polymer, the polysaccharides-based hydrogels exhibit several advantages, such as renewability, biodegradability and cheaperness because the raw materials are locally abundant. The biocompatibility of polysaccharides is very interesting characteristic of material, mainly on biomedical applications. In this research, we converted polysaccharide extracted from seaweed into hydrogel.

Kappa carrageenans are linear polysaccharides sulfated galactan extracted from red seaweed (Rhodophyta), such as Kappaphycus alvarezii (known as Eucheuma cottonii in industry) which is well cultivated in Indonesia. This natural polymers comprise of repeating units of (1,3)-D-galactopyranose and (1,4)-3,6-anhidro- $\alpha$-Dgalactopyranose with sulfate groups in a certain amount and position (Campo et al., 2009). The presence of hydroxyl groups and sulfate groups in carrageenan structure cause the carageenan tend to be hydrophilic. Kappa carageenans have ability to form thermoreversible gel. Because of their gelling ability, carrageenans are widely used as agent for thickening and gelling in food and nonfood industries (Van de Velde et al., 2002), and potent as raw materials of hydrogels (Hoffman, 2002). Some gel applications need hydrogel properties which mainly can absorb and keep water without dissolution. For improving the stability in aqueous, the kappa carrageenan structures must be chemically crosslinked to produce hydrogel structure.

Preparation of hydrogel of kappa carrageenan graft polyacrylamide has been studied by Abd El-Mohdy and Abd El-Rehim (2009). Previous studies reported the preparation of kappa carrageenan base hydrogel by crosslinking with epichlorohydrine (Keppeler et al., 2009), $\mathrm{CaCl}_{2}$ (Pascalau et al., 2012), and genipin (Meena et al., 2007). To our best knowledgde, crosslinking carrageenan with glutaraldehyde into hydrogel film has not been reported. In this work, glutaraldehyde was chosen as the crosslinker. Glutaraldehyde is easily available and inexpensive. Its aqueous solution is known as an effective crosslinker for natural polymer, such as guargum (Cunha et al., 2005), 
alginate (Geroge \& Abraham, 2007), chitosan (Shang et al., 2008), and collagen (Verissimo et al., 2010). The previous studies stated that prepared hydrogels were suitable for applications in biomedical fields.

The gel properties of carrageenan are function of the recovery method from seaweed (Campo et al., 2009; Montolalu et al., 2006). Alkali treatment in carrageenan recovery from seaweed improved the gel strength of obtained carrageenan (Hilliou et al., 2006; Navarro et al., 2007). This research was focused on the evaluation of the effect of carrageenan produced with different extraction procedure of Kappaphycus alvarezii seaweed on the properties of prepared hydrogel. The hydrogels were prepared by using film immersion in glutaraldehyde solution and then followed by thermal curing method. The swelling properties of obtained hydrogel at different $\mathrm{pH}$ media was also studied for evaluating the suitability of hydrogel application.

\section{Method}

\subsection{Materials}

Seaweeds of Kappaphycus alvarezii were harvested from Makasar, South Sulawesi, Indonesia. The seaweeds were soaked in water for $2 \mathrm{~h}$, and then washed using tap water several times to eliminate all impurities such as salt and sand. After washing, the seaweeds were cut into about $1 \mathrm{~cm}$ length, and finally sun dried to constant weight. The 'clean seaweed' sample was kept in a dry state until further processing was done. Technical grade of potassium hydroxide (purity $88 \%$ ) was used as alkali treatment before extraction process. Glutaraldehyde (wt $25 \%$ solution in water (Merck)) and all other chemicals were purchased and used without further purification.

\subsection{Carrageenan Preparation}

The procedure of carrageenan recovery from Kappaphycus alvarezii followed the previously reported method (Distantina et al., 2011) with minor modification. The clean seaweed was treated using KOH solution before being extracted. Thirty gram of seaweed was soaked in $\mathrm{KOH} 0.3 \mathrm{~N}$ overnight and then heated at $60{ }^{\circ} \mathrm{C}$ for 30 min. After alkali treatment, the seaweed was washed with tap water and neutralized with $\mathrm{HCl} 0.1 \mathrm{~N}$. A specified amount of distilled water was heated in a beaker as an extractor. After the temperature of the water reached $80^{\circ} \mathrm{C}$, the seaweed was then added into solvent, and the time of extraction started to be counted. A constant ratio of seaweed weight to solvent volume $(1: 50 \mathrm{~g} / \mathrm{mL})$ was maintained by adding hot water. After $1 \mathrm{~h}$ extraction, the filtrate was separated from residue and immediately poured into $4.5 \mathrm{~L}$ of cold $\left(5{ }^{\circ} \mathrm{C}\right)$ ethanol $(\mathrm{wt} 90 \%)$ which caused precipitation of polysaccharides. The precipitation was allowed for $30 \mathrm{~min}$ while a gentle stirring was done. The precipitated carrageenans were collected. The obtained carrageenans were called as alkali treated carrageenan (AT). The other procedure of carrageenan recovery without alkali treatment step produced nonalkali treated carrageenan (NAT).

\subsection{Film Preparation}

Carrageenan films both AT and NAT were prepared by dissolution of the precipitated carrageenan in distilled water. The mixtures were heated and stirred until homogeneous solutions were obtained. The solutions were poured into plastic plate and allowed to solidify and then dried at room temperature to constant weights. The obtained films were cut into $1.5 \mathrm{~cm} \times 1.5 \mathrm{~cm}$ pieces and the weight of each piece film was about 0.03-0.04 gram.

\subsection{Carrageenan Characterization}

The resulting carrageenans both AT and NAT were analyzed to evaluate their sulfate content, gel strength, and intrinsic viscosity. Percent sulfate content was determined using the method of sulfate hydrolysis followed by precipitation sulfate as barium sulfate (Jeffery et al., 1989). Percent sulfate content was calculated based on weight of free sulfate sample. The gel strength was determined using method described by Falshaw et al. (1998) with minor modifications. The dried carrageenan was diluted by $\mathrm{KCl} 0.09 \mathrm{M}$ with heating to obtain a $1.5 \%(\mathrm{w} / \mathrm{v})$ carrageenan solution. Intrinsic viscosity was determined experimentally from measurement of the viscosity of dilute concentration of carrageenan aqueous solution $(0.0038-0.0329 \mathrm{~g} / \mathrm{dL})$ using an Oswald glass capillary viscometer (Brand Germany, no.1) at room temperature. Intrinsic viscosity was evaluated by extrapolation of reduced viscosity to the value at zero carrageenan concentration.

\subsection{Film Crosslinking}

We prepared control (noncrosslinked) and crosslinked films. GA $4 \mathrm{wt} \%$ as the crosslinker was prepared by diluting GA $25 \mathrm{wt} \%$ with distilled water. For preparing the crosslinked film, the carrageenan films were immersed in crosslinker for $2 \mathrm{~min}$. The surface of film were wiped with filter cloth and then cured at $110{ }^{\circ} \mathrm{C}$ in oven for $25 \mathrm{~min}$. The crosslinked film was soaked in water with stirring for $1 \mathrm{~min}$ and then in ethanol for $4 \mathrm{~h}$ to remove unreacted GA. The wet hydrogels were dried at room temperature to a constant weight. 


\subsection{Hydrogel Characterization}

Molecular groups were identified using FTIR spectrometer (Shimadzu IR Prestige-21). Both noncrosslinked and crosslinked film were powdered. Infrared spectra were obtained by using $\mathrm{KBr}$ pellet method with 10 scans and $16 \mathrm{~cm}^{-1}$ resolution. Assignment of IR spectra of obtained hydrogels was based on spectroscopy data summarized by Pereira et al. (2009).

For determining the value of swelling ability, a piece of hydrogel film was weighted and then placed in distilled water of $10 \mathrm{~mL}$. The swelling degree was evaluated by measuring the weight before soaking (Md) and the weight after soaking $(\mathrm{Mw})$ in solution as function of soaking time at room temperature. All weight measurements were conducted on a pan balance (Ohaus) having an accuracy up to fourth decimal. Swelling degree (SD) was calculated as Equation (1). Each experiment was done at least one duplicate run and the mean value was used to display the data.

$$
\mathrm{SD}=(\mathrm{Mw}-\mathrm{Md}) / \mathrm{Md}
$$

To study the effect of extraction method on the swelling degree, the swelling tests were conducted in water ( $\mathrm{pH} \sim 7$ ), phosphate buffer ( $\mathrm{pH} \sim 7.4)$, and $\mathrm{NaOH} 0.1 \mathrm{~N}(\mathrm{pH} \sim 13)$.

\section{Results and Discussion}

\subsection{Carrageenan Crosslinking}

Figure 1 shows the FTIR spectra of control (noncrosslinked) film and crosslinked film. Sample A and C were noncrosslinked carrageenan film extracted from alkali treatment (AT) and nonalkali treatment (NAT), respectively. Sample B and D were crosslinked carrageenan films from AT and NAT, respectively. The characteristic infrared peaks of samples are presented in Figure 1 and Table 1.

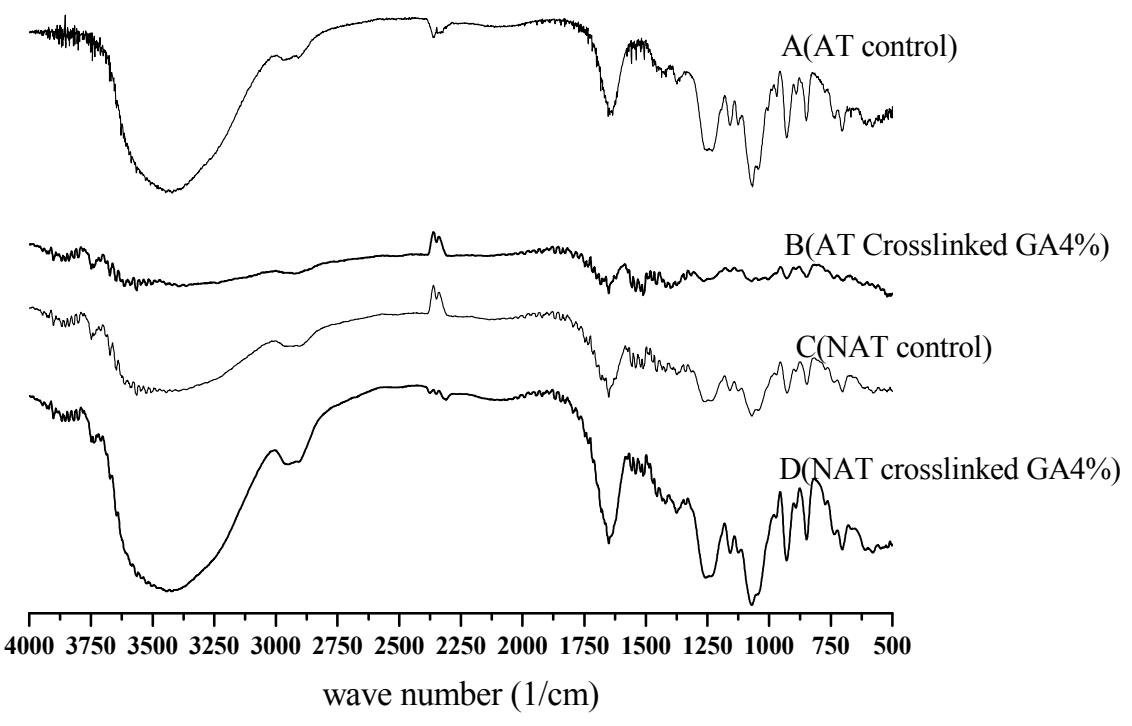

Figure 1. FTIR spectra of noncrosslinked (control) and crosslinked carrageenan film

Table 1. Characteristic IR peaks present in the sample

\begin{tabular}{llrrrr}
\hline & & \multicolumn{4}{c}{ Peak $\left(\mathrm{cm}^{-1}\right)^{\mathrm{b}}$} \\
\cline { 3 - 6 } \multicolumn{1}{c}{ Functional groups } & \multicolumn{1}{c}{ Peak $\left(\mathrm{cm}^{-1}\right)^{\mathrm{a}}$} & Sample A & Sample B & Sample C & Sample D \\
\hline Galactose-4-sulfate & $840-850$ & 848.68 & 848.68 & 848.68 & 848.68 \\
3,6 Anhydro-galactose & $925-935$ & 925.83 & 933.55 & 933.55 & 933.55 \\
Ester sulfate & $1210-1260$ & 1257.59 & 1265.30 & 1273.02 & 1265.30 \\
Hydroxyl & $3200-3600$ & 3448.72 & 3448.72 & 3417.86 & 3448.72 \\
\hline
\end{tabular}

${ }^{a}$ Literature values (Pereira et al., 2009).

${ }^{\mathrm{b}}$ Observed values. 
In this research, infrared spectra of extracted carrageenan from Kappaphycus alvarezii for both AT and NAT show the features of kappa carrageenan. The changes of sample peak before and after crosslinking could not be seen clearly, as shown in Figure 1. Glutaraldehyde has been used as crosslinker for polymer containing hydroxyl groups. Some previous researchers reported that hydroxyls from polymer react with aldehyde forming hemi acetal structure (Chen et al., 2012; Kim et al., 1994; Lee et al., 2005; Mansur et al., 2008). The peak ascribed to acetal groups did not appear in observed FTIR spectra (Figure 1). This was probably caused by the low amount of acetal groups in crosslinked film.

Although it is difficult to exactly determine the conversion of crosslinked polymer, the physical characteristics of crosslinked polymer, especially swelling behavior, indirectly demonstrates the success of crosslinking reaction (Keppeler et al., 2009). The crosslinking is also expressed by the stability of the obtained hydrogel in aqueous solution as characterized by a significant decrease of swelling degree.

Figure 2 shows the values of swelling degree as function of swelling time in distilled water. The swelling degree expresses as gram of water uptake per gram of carrageenan film. The control films swelled and rapidly disintegrated in less than $30 \mathrm{~min}$ for both AT and NAT carrageenan. This facts show that carrageenan is a hydrophilic polymer. When it is contacted with water, it will swell and then gradually dissolve or disintegrate into the water. Therefore, when it is used carrageenan as the hydrogel, it needs to be modified to improve its solubility.

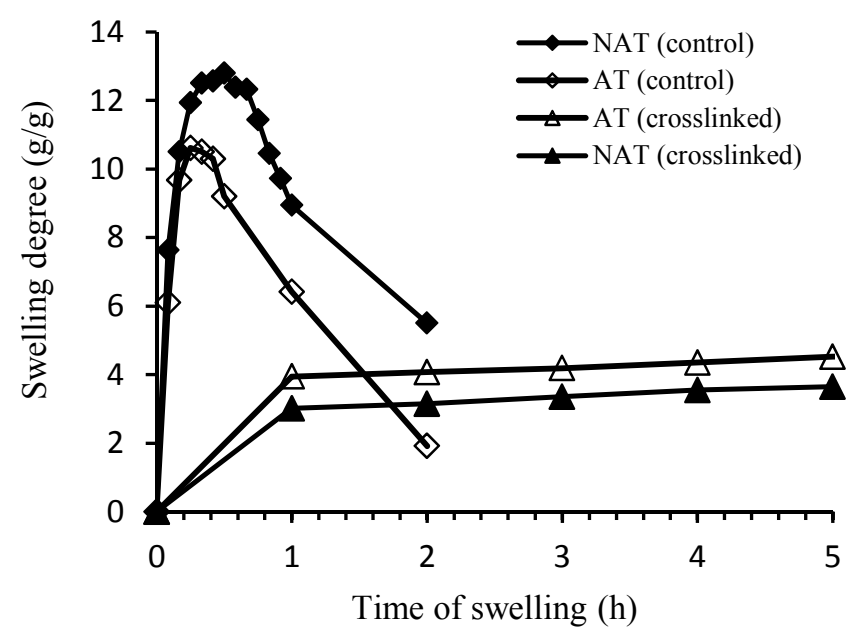

Figure 2. Comparison of control (noncrosslinked) and crosslinked film in distilled water

Comparing control and crosslinked films, the crosslinked hydrogels from AT or NAT were more stable at water (Figure 2). Crosslinked films exhibited hydrogel characteristics which did not dissolve easily in water and became water resistant indicating the more stable structures comparatively to the noncrosslinked film. The rigid structure of crosslinked film was formed by crosslinking. Crosslinking procedure by film immersion followed by high temperature curing can drive the reaction between hydroxyl groups of carrageenan and aldehydes of GA to form rigid crosslink structures. The decreasing of swelling degree of crosslinked film indicates the presence of crosslinked structure (Pascalau et al., 2012; Rasool et al., 2010). The crosslinked films showed lower swelling degree compared with the control, as observed from Figure 2.

Compared with commonly used hydrogel preparation procedure homogeneous system crosslinking in which the GA solution is directly added to the polymer solution, the film immersion and curing method used in this present research is simpler and more rapid. In addition, the amount of GA as crosslinker can be easily adjusted for controlling the hydrogel's swelling properties. Finally, the removal of unreacted GA is also easily conducted so that the hydrogel has far lower cytotoxicity.

\subsection{Effect of Extraction Procedure on Swelling Degree}

Crosslinked nonalkali treated carrageenan showed little ability to absorb water in buffer phosphate and $\mathrm{NaOH}$ $0.1 \mathrm{M}$ media, but crosslinked alkali treated carrageenan showed significantly higher swelling ability, as observed from Figures 3 and 4 . The crosslinked film of NAT quickly reached the equilibrium swelling degree in less than $2 \mathrm{~h}$ of immersion. 


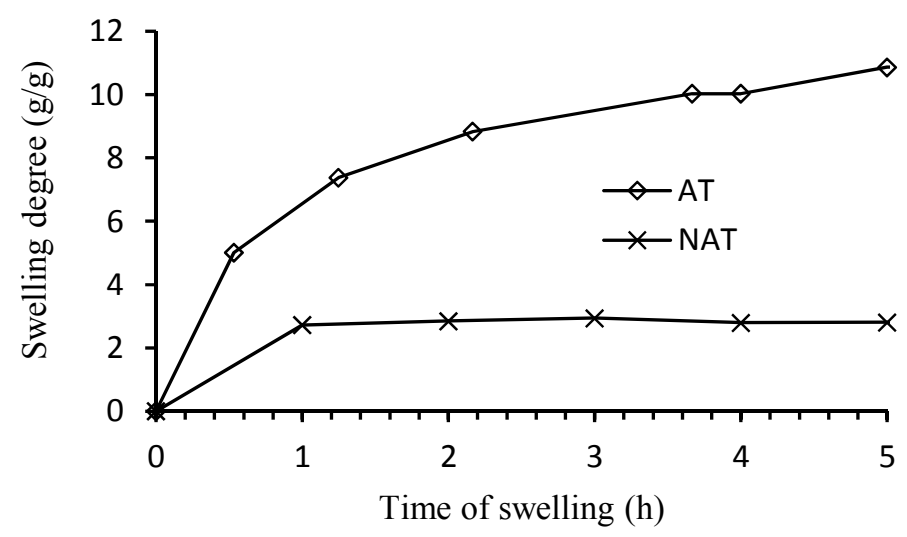

Figure 3. Swelling degree of crosslinked film in phosphate buffer

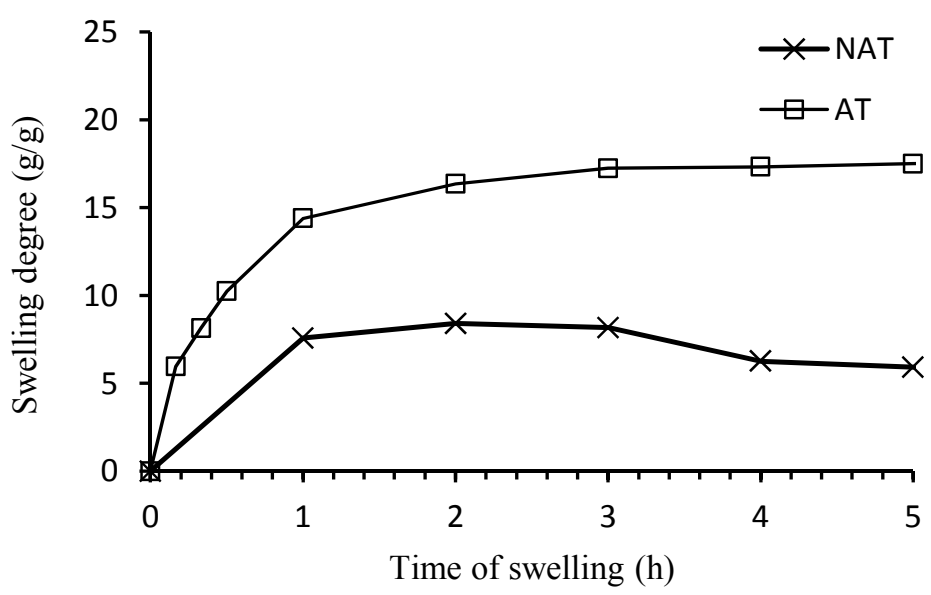

Figure 4. Swelling degree of crosslinked film in $\mathrm{NaOH} 0.1 \mathrm{M}$

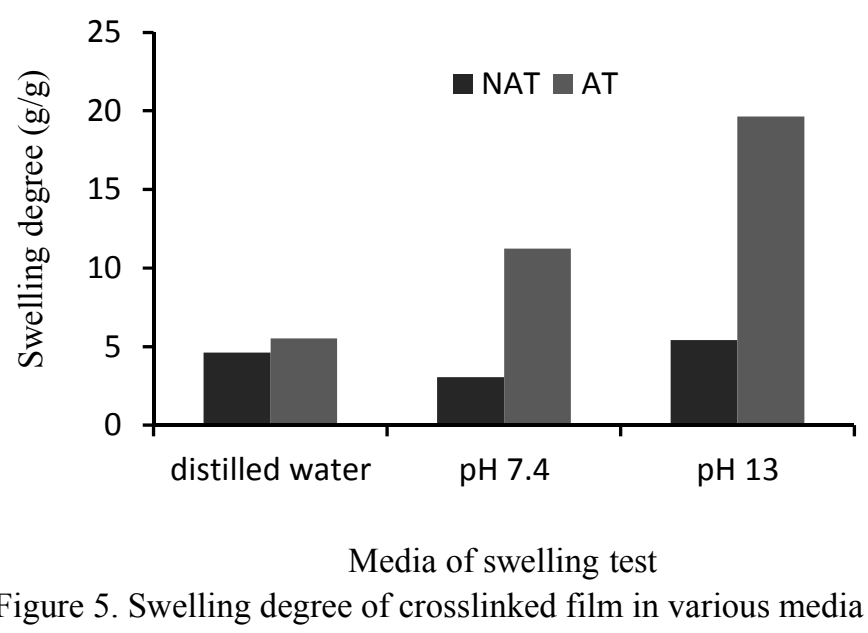

Figure 5 presents results of swelling degree measurement after $24 \mathrm{~h}$ of immersion in distilled water ( $\mathrm{pH} \sim 7$ ), phosphate buffer $(\mathrm{pH} 7.4)$ and in $\mathrm{NaOH}$ solution $(\mathrm{pH} 13)$. The effect of carrageenan recovery method on hydrogel swelling behavior is also presented in Figure 5. At distilled water, the crosslinked film of AT showed slightly higher value of swelling degree than that crosslinked film of NAT. When immersed at phosphate buffer and $\mathrm{NaOH} 0.1 \mathrm{M}$, the AT and NAT crosslinked film exhibited considerably different values of swelling degree. It is shown that the values of swelling degree of hydrogel prepared from AT were higher at all media tested as compared to the NAT. This is probably caused by the different structure between AT and NAT resulted during 
carrageenan recovery process.

The different characteristics of NAT and AT carrageenan are displayed in Table 2. Alkali treatment in carrageenan extraction is an important and well-known reaction. It is used commercially to enhance gelation behavior (Campo et al., 2009). The reaction is shown in Figure 6. From Table 2, it can be seen that alkali treatment reduced the sulfate content from $19.5 \%$ for NAT into $16.7 \%$ for AT, indicating that carrageenan reaction occurred. Intrinsic viscosity value corresponds to the molecular weight. It was no significant difference of intrinsic viscosity between NAT and AT, expressing no polymer degradation occured during alkali treatment. Alkali treatment using $\mathrm{KOH} 0.3 \mathrm{~N}$ in this research caused slight improvement of gel strength.

Table 2. Characteristics of carrageenan extracted from seaweed

\begin{tabular}{cccc}
\hline Carrageenan & Sulfate $(\%)$ & Gel strength $\left(\mathrm{g} / \mathrm{cm}^{2}\right)$ & {$[\mu](\mathrm{dL} / \mathrm{g})$} \\
\hline NAT & 19.52 & 191.09 & 51 \\
AT & 16.69 & 208.96 & 54 \\
\hline
\end{tabular}

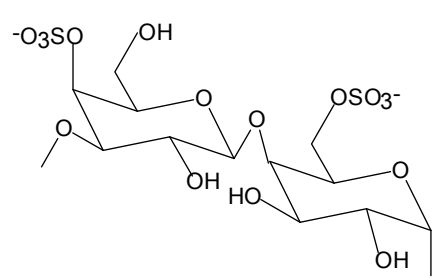

Mu-carrageenan

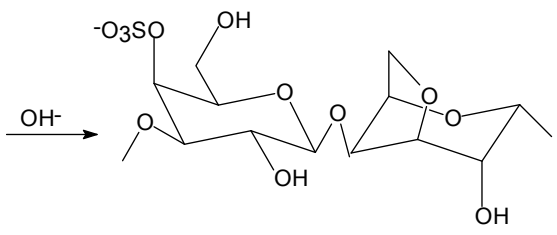

Kappa-carrageenan

Figure 6. Kappa carrageenan reaction

$\mathrm{Mu}(\mu)$ carrageenan is the biological precursor of kappa $(\mathrm{k})$ carrageenan. The seaweeds are usually extracted with alkali at elevated temperature to transform the biological precursor, $\mu$ carrageenan into kappa carrageenan (Ciancia et al., 1993; Van de Velde et al., 2002). The natural precursor of kappa carrageenan, $\mu$ carrageenan is non gelling carrageenan with galactose units in the ${ }^{4} \mathrm{C}_{1}$ conformation. The occurrence of ${ }^{4} \mathrm{C}_{1}$ conformation prevents the formations of helical strands and the gelation of the carrageenan. The ${ }^{1} \mathrm{C}_{4}$ conformation of the 3,6-anhydro-D-galactose units in kappa carrageenan allows a helical structure, which is essential for the gel forming properties (Falshaw et al., 1998; Van de Velde et al., 2002). Therefore, the carrageenan reaction produces gel forming structure, the 3,6-anydro-D-galactose unit, chemical bonds that create a tridimensional hydrophilic structure. Alkali treatment in carrageenan recovery increases the amount of 3,6-anhydro-galactose unit of gel forming structure (Ciancia et al., 1993). The occurrence of this reaction can be also indicated by the reduction of sulfate content in carrageenan produced by alkali treatment.

Carrageenan of NAT also contained the 3,6-anhydro-D-galactose, as depicted by FTIR spectra (Figure 1). According to Van de Velde et al. (2002), naturally the 3,6-anhydro-D-galactose are formed enzymatically by a sulfohydrolase in the seaweed. Therefore, lower 3,6-anhydro-D-galactose unit in NAT probably causes the lower swelling degree compared to those of AT. The different swelling behavior of obtained hydrogel shows that alkali treatment in carrageenan recovery strongly determines the characteristic of hydrogel.

\subsection{Effect of pH on Swelling Properties}

Understanding the swelling behavior of hydrogels in the presence of ions is important from both practical and theoretical points of view. The high water content of the hydrogels and $\mathrm{pH}$ responsive properties provide them important characteristics that support personal hygienic (Hoffman, 2002), agricultural applications (Abd El-Mohdy \& Abd El-Rehim, 2009), and tissue engineering (Lee et al., 2005). In this research, the crosslinked films were highly unstable in acidic $\mathrm{pH}$. The swelling degree of crosslinked film at $\mathrm{pH} 1.2$ could not be measured because the structure of hydrogel collapsed and disintegrated rapidly.

As shown in Figure 5, significant changes on swelling degree of crosslinked NAT film in different $\mathrm{pH}$ media was not observed. Maximum swelling degree of NAT hydrogels at all tested media was almost constant, about $5 \mathrm{~g} / \mathrm{g}$. The swelling degree of prepared hydrogels from AT in various $\mathrm{pH}$ solution was appreciably different compared to the swelling values in distilled water. The swelling degree at distilled water was lower than that at buffer phosphate solution. The swelling degree at $\mathrm{pH} \sim 13$ showed the highest value. Swelling degree of AT hydrogel 
increased by increasing $\mathrm{pH}$ solution from about $5 \mathrm{~g} / \mathrm{g}$ for neutral $\mathrm{pH}$ to $20 \mathrm{~g} / \mathrm{g}$ for $\mathrm{pH} \sim 13$. Crosslinked films from NAT did not show the $\mathrm{pH}$ sensitive properties, but the crosslinked films from AT exhibited the $\mathrm{pH}$ responsive properties. Therefore, the obtained crosslinked hydrogels of AT film were chosen for studying the effect of $\mathrm{pH}$ on the swelling properties.

The presence of sulfate groups and hydroxyl groups in carrageenan structure make these hydrogels $\mathrm{pH}$ sensitive. Carrageenans contain at least one sulfate group per repeating unit, so the ionic concentrations inside are supposed to be high, which also means carrageenans are anionic polymers. All of the $\mathrm{pH}$ sensitive polymers contain acidic group, such as carboxylic and sulfonic acids, or basic group, such as ammonium salts, that either accept or release protons in response to changes in environmental pH (Gerlach et al., 2005; Rasool et al., 2010; Qiu \& Park, 2001; Zhang et al., 2005).

When the system $\mathrm{pH}$ is higher than $\mathrm{pKa}$ of ionizable group, most of the group are dissociated, leading to the significant decreasing in hydrogen bonds. The value $\mathrm{pKa}$ of sulfonic acid is around 2.8. At $\mathrm{pH}$ media is higher than 2.8 , the ionic groups $-\mathrm{OSO}_{3} \mathrm{H}$ are deprotonated resulting ionic groups $-\mathrm{OSO}_{3}{ }^{-}$at hydrogel structure. The charges of hydrogel network change in aqueous media. Anionic polymers will be ionized at high $\mathrm{pH}$, while cationic polymers will be ionized at low pH (Samchenko et al., 2011; Zhang et al., 2005). Due to the increase number of negatively charged, the electrostatic repulsion becomes dominant. These same negatively charged groups are repelled by each other. The negatively charged sulfate groups on different chains induce the electrostatic repulsion, as a result the distance between the chains increase. The space of network becomes larger, so that the network becomes more permeable to large molecules and much water can penetrate into the network, leading to the higher swelling degree. Comparing to distilled water $(\mathrm{pH} 7)$ and $\mathrm{NaOH} 0.1 \mathrm{M}(\mathrm{pH} 13)$ as media of swelling, the higher $\mathrm{pH}$ tend to increase the number of dissociated sulfate facilitating more amount of water diffusion into network to swell the hydrogel.

\section{Conclusion}

Kappa carrageenan hydrogels have been successfully prepared by crosslinking with GA using film immersion and followed by thermal curing. The procedure of carrageenan recovery from seaweed significantly affects the properties of obtained hidrogel. Comparing to the films on nonalkali treated carrageenan, the film of alkali treated carrageenan exhibited higher swelling degree. The prepared hydrogel of alkali treated carrageenan showed responsive to the change of $\mathrm{pH}$. The $\mathrm{pH}$ sensitive properties indicate that glutaraldehyde crosslinked kappa carrageenan film may be developed as new natural based polymer with $\mathrm{pH}$ responsive properties.

\section{Acknowledgements}

The authors would like to acknowledge the Directorate General of Higher Education, Ministry of National Education, Indonesia, for financial support of this work through research grant of Penelitian Unggulan PT 2013, Sebelas Maret University and the scholarship of doctorate program (BPPS) at Gadjah Mada University.

\section{References}

Abd El-Mohdy, H. L., \& Abd El-Rehim, H. A. (2009). Radiation synthesis of kappa-carrageenan/acrylamide graft copolymers as superabsorbents and their possible applications. Journal of Polymer Research, 16, 63-72. http://dx.doi.org/10.1007/s10965-008-9203-5

Campo, V. L., Kawano, F. F., Silva Junior, D. B., \& Carvalho, I. (2009). Carrageenans: biological properties, chemical modifications and structural analysis. Carbohydrate Polymers, 77, 167-180. http://dx.doi.org/10.1016/j.carbpol.2009.01.020

Chen, P., Wu, R., Wang, J., Liu, Y., Ding, C., \& Xu, S. (2012). One-pot preparation of ultrastrong double network hydrogels. Journal of Polymer Research, 19, 9825. http://dx.doi.org/10.1007/s10965-012-9825-5

Ciancia, M., Noseda, M. D., Matulewicz, M. C., \& Cerezo, A. S. (1993). Alkali-modification of carrageenans: Mechanism and Kinetics in the kappa/iota-, mu/nu- and lambda-series. Carbohydrate Polymers, 20, 95-98. http://dx.doi.org/10.1016/0144-8617(93)90083-G

Cunha, P. L. R., Castro, R. R., Rocha, F. A. C., de Paula, R. C. M., \& Feitosa, J. P. A. (2005). Low viscosity hydrogel of guar gum: Preparation and physicochemical characterization. International Journal of Biological Macromolecules, 37, 99-104. http://dx.doi.org/10.1016/j.ijbiomac.2005.09.001

Distantina, S., Wiratni, Fahrurrozi, M., \& Rochmadi. (2011). Carrageenan properties extracted from Eucheuma cottonii, Indonesia. World Academy of Science, Engineering and Technology, 78, 738-742.

Falshaw, R., Furneaux, R. H., \& Stevenson, D. E. (1998). Agars from nine species of red seaweed in the genus curdie (glacilariaceae, rhodophyta). Carbohydrate Research, 308, 107-115. 
http://dx.doi.org/10.1016/S0008-6215(98)00049-4

George, M., \& Abraham, T. E. (2007). pH sensitive alginate-guar gum hydrogel for controlled delivery of protein $\begin{array}{lllll}\text { drugs. International Journal of } & \text { Pharmaceutics, } & 335, & 123-129 .\end{array}$ http://dx.doi.org/10.1016/j.ijpharm.2006.11.009

Gerlach, G., Guenther, M., Sorber, J., Suchaneck, G., Arndt, K., \& Richter, A. (2005). Chemical and pH sensors based on the swelling behavior of hydrogels. Sensors and Actuators B, 111-112, 555-561. http://dx.doi/org/10.1016/j.snb.2005.03.040

Hilliou, L., Larotonda, F. D. S., Abreu, P., Ramos, A. M., Sereno, A. M., \& Goncalves, M. P. (2006). Effect of extraction parameters on the chemical structure and gel properties of $\mathrm{k} / \mathrm{i}$-hybrid carrageenans obtained from $\begin{array}{llll}\text { Mastocarpus } \quad \text { stellatus. } & \text { Biomolecular 201-208. }\end{array}$ http://dx.doi.org/10.1016/j.bioeng.2006.04.003

Hoffman, A. S. (2002). Hydrogel for biomedical applications. Advanced Drug Delivery Reviews, 43, 3-12. http://dx.doi.org/10.1016/S0169-409X(01)00239-3

Jeffery, G. H., Bassett, J., Mendham, J., \& Denney, R. C. (1989). Vogel's textbook of quantitative chemical analysis (5th ed.). pp. 490-493. Avon, Great Britain: Bath press.

Keppeler, S., Ellis, A., \& Jacquier, J. C. (2009). Cross-linked carrageenan beads for controlled release delivery systems. Carbohydrate Polymers, 78, 973-977. http://dx.doi.org/10.1016/j.carbpol.2009.07.029

Kim, K., Lee, S., \& Han, N. W. (1994). Kinetics of crosslinking reaction of PVA membrane with glutaraldehyde. Korean Journal of Chemical Engineering, 11, 41-47. http://dx.doi.org/10.1007/BF02697513

Lee, C. T., Kung, P. H., \& Lee, Y. D. (2005). Preparation of poly(vinyl alcohol)-chondroitin sulfate hydrogel as matrices in tissue engineering. Carbohydrate Polymers, 61, 348-354. http://dx.doi.org/10.1016/j.carbpol.2005.06.018

Mansur, H. S., Sadahira, C. M., Souza, A. N., \& Mansur, A. A. P. (2008). FTIR spectroscopy characterization of poly (vinyl alcohol) hydrogel with different hydrolysis degree and chemically crosslinked with glutaraldehyde. Material Science and Engineering C, 28, 539-548. http://dx.doi.org/10.1016/j.msec.2007.10.088

Meena, R., Prasad, K., \& Siddhanta, A. K. (2007). Effect of genipin, a naturally occuring crosslinker on the properties of kappa-carrageenan. International Journal of Biological Macromolecules, 41, 94-101. http://dx.doi.org/10.1016/j.ijbiomac.2007.01.008

Montolalu, R. I., Tashiro, Y., Matsukawa, S., \& Ogawa, H. (2007). Effect of Extraction Parameters on Gel Properties of Carrageenan from Kappaphycus alvarezii (Rhodophyta). Journal of Applied Phycology, 20, 521-526. http://dx.doi.org/10.1007/s10811-007-9284-2

Navarro, D. A., Flores, M. L., \& Stortz, A. C. (2007). Microwave-assisted desulfation of sulfated polysaccharides. Carbohydrate Polymers, 69, 742-747. http://dx.doi.org/10.1016/j.carbpol.2007.02.009

Pascalau, V., Popescu, V., Popescu, G. L., Dudescu, M. C., Borodi, G., Dinescu, A., ... Paul, M. (2012). The alginate/k-carrageenan ratio's influence on the properties of the cross-linked composite films. Journal of Alloys and Compounds. http://dx.doi.org/10.1016/j.jallcom.2011.12.026

Peppas, A. N. (2004). Hydrogels In: Biomaterial Science: an Introduction to Material in Medicine (2nd ed.). pp. 100-106. Ratner et al., ed. California: Elsevier Academic Press.

Pereira, L., Amado, A. M., Critley, A. T., Van de Velde, F., \& Ribeiro-Claro, P. J. A. (2009). Identification of selected polysaccharides (phycocolloids) by vibrational spectroscopy (FTIR-ATR and FT-Raman). Food Hydrocolloids, 23, 1-7. http://dx.doi.org/10.1016/j.foodhyd.2008.11.014

Qiu, Y., \& Park, K. (2001). Environment-sensitive hydrogels for drug delivery. Advanced Drug Delivery Reviews, 53, 321-339. http://dx.doi.org/10.1016/S0169-409X(01)00203-4

Rasool, N., Yasin, T., Heng, J. Y. Y., \& Akhter, Z. (2010). Synthesis and characterization of novel pH-, ionic strength and temperature- sensitive hydrogel for insulin delivery. Polymers, 51, 1687-1693. http://dx.doi.org/10.1016/j.polymer.2010.02.013

Samchenko, Y., Ulberg, Z., \& Korotych, O. (2011). Multipurpose smart hydrogel systems. Advances in Colloid and Interface Science, 168, 247-262. http://dx.doi/org/10.1016/j.cis.2011.06.005

Shang, J., Shao, Z., \& Chen, X. (2008). Chitosan-based electroactive hydrogel. Polymer, 49, 5520-5525. 
http://dx.doi.org/10.1016/j.polymer.2008.09.067

Van de Velde, F., Knutsen, S. H., Usov, A. I., Rollema, H. S., \& Cerezo, A. S. (2002). 1H and 13C High resolution NMR spectroscopy of carrageenans: aplication in research and industry. Trend in Food Science and Technology, 13, 73-92. http://dx.doi.org/10.1016/S0924-2244(02)00066-3

Verissimo, D. M., Leitao, R. F. C., Ribeiro, R. A., Figueiro, S. D., Sombra, A. S. B., Goes, J. C., \& Brito, G. A. C. (2010). Polyanionic collagen membranes for guided tissue regeneration: Effect of progressive glutaraldehyde cross-linking on biocompatibility and degradation. Acta Biomaterialia, 6, 4011-4018. http://dx.doi.org/10.1016/j.actbio.2010.04.012

Zhang, R., Tang, M., Bowyer, A., Eisenthal, R., \& Hubble, J. (2005). A novel pH- and ionic-strength-sensitive carboxy methyl dextran hydrogel. Biomaterials, 26, 4677-4683. http://dx.doi.org/10.1016/j.biomaterials.2004.11.048

\section{Copyrights}

Copyright for this article is retained by the author(s), with first publication rights granted to the journal.

This is an open-access article distributed under the terms and conditions of the Creative Commons Attribution license (http://creativecommons.org/licenses/by/3.0/). 